\title{
Priapism in children: review of pathophysiology and treatment
}

\author{
Lisieux Eyer de Jesus, ${ }^{1}$ Samuel Dekermacher ${ }^{2}$
}

\begin{abstract}
Objective: Priapism may cause serious sequelae concerning the future sex life of the patient, as it can determine impotence, erectile dysfunction or psychogenic sexual aversion. It is a common symptom of sickle cell disease in children and adolescents. There are few good quality evidence manuscripts about the problem in current medical literature.

Sources: Literature review on the databases MEDLINE and LILACS covering the period from 1966 to 2008.

Summary of the findings: The basis for the treatment of low flow priapism includes treating sickle cell disease and the usage of intracavernous adrenergic agents as necessary. Surgery is indicated in a minority of cases. The treatment of pediatric cases demands dose adjustments, adequate drug choice and sedoanalgesia to cover procedures involving pain or trauma.

Conclusions: A new physiopathologic theory concerning sickle cell disease, which questions the traditional vascular blockage mechanisms by deformed red cells and proposes that endothelial inflammatory activation is the main cause of clinical problems, allows to propose new therapeutic maneuvers to solve sickle cell priapism. The absence of good quality evidence to treat sickle cell priapism suggests the necessity to conduct good prospective multicenter protocols to investigate the condition.
\end{abstract}

J Pediatr (Rio J). 2009;85(3):194-200: Priapism, sickle cell disease, children.

\section{Introduction}

Priapism can present in childhood and adolescence, commonly to emergency services, and data about the disease and its therapy are rare in literature, especially concerning pediatric cases. The purpose of this manuscript is to review and to systematize the procedures used to treat children with priapism. We reviewed all the pertinent literature in Portuguese, Spanish, French and English using the databases MEDLINE and LILACS from 1966 to June 2008 using the keywords priapism and/or sickle cell disease (SCD), limiting ages from 0 to 18 years old.

Priapism in childhood commonly presents as a common symptom of SCD especially after puberty, mainly as low flow or as a complication of penile trauma (normally high flow, non-ischemic episodes). This phenotypic manifestation of SCD can cause persistent impotence, erectile dysfunction and behavioral problems in the sexual realm, as affected individuals fear the induction of an episode of painful erection in the course of normal sexual activity, which is the most common cause of priapism episodes after puberty. ${ }^{1}$

\section{Pathophysiology}

SCD is genetically determined by a mutation in the $\beta$-globin chain of hemoglobin. The erythrocytes contain a deviant form of hemoglobin, hemoglobin $S$, whose biochemical characteristics cause functional problems. SCD can exhibit various manifestations (called pathologic phenotypes), which include pulmonary hypertension, cerebral vascular accidents, lower extremity ulcerations, osteonecrosis, painful crises, and priapism among other less common clinical problems. Priapism in sickle cell patients has been classically attributed to vasoocclusion episodes, secondary to the deformation of red blood cells containing hemoglobin $\mathrm{S}$ by hypoxemia and acidosis in the corpora cavernosa (CC) (caused by vasoconstriction, hypovolemia or stasis in the CC during physiologic erection), causing microvascular obstruction, in a vicious cycle: red cell deformation causes vascular obstruction and secondary ischemia, which promotes new red cell deformation (vicious cycle theory, accepted since the 1940s). ${ }^{2}$

1. Departamento de Cirurgia Pediátrica, Hospital Universitário Antônio Pedro, Niterói, RJ, Brazil. Departamento de Cirurgia Pediátrica, Hospital dos Servidores do Estado, Rio de Janeiro, RJ, Brazil. TCBC, T-CIPE.

2. Departamento de Cirurgia Pediátrica, Hospital dos Servidores do Estado, Rio de Janeiro, RJ, Brazil. TiSBU, TCBC.

No conflicts of interest declared concerning the publication of this article.

Suggested citation: de Jesus LE, Dekermacher S. Priapism in children: review of pathophysiology and treatment. J Pediatr (Rio J). 2009;85(3):194-200. Manuscript received Sep 22 2008, accepted for publication Nov 122008.

doi:10.2223/JPED.1897 
Experimental studies and clinical experience have raised doubts about this model since the 1940s, when it was demonstrated experimentally that SCD patients intentionally exposed to hypoxemic conditions did not present problems. ${ }^{3-5}$ It is known that patients with SCD and chronic persistent hypoxemia (for example, cyanotic heart diseases) can survive and that orthopedic surgeries of the extremities can be performed using tourniquets without any problems in these patients. Anatomic vascular lesions have been demonstrated in various organic territories in SCD, by autopsy or arteriography, suggesting that vascular problems in these patients may not depend on episodes of gelation of abnormal hemoglobin (causing deformation of red blood cells). In the neurologic and chronic pulmonary lesions of sickle cell patients it has been demonstrated that the pathophysiology includes vascular remodeling before the onset of symptoms. ${ }^{6,7}$

A new model of the pathophysiology of SCD has been proposed from the 1970 s and 1980s, based on the mediating function of the vascular endothelium in the microcirculation (inflammatory theory). SCD is characterized by hemolysis, whose intensity varies across individuals and at different moments in a patient's life. The instability of the hemoglobin $S$ molecule leads to the exposure of the highly oxidative group heme and causes degradation of the cellular membrane, releasing hemoglobin and arginase into the extracellular environment, in a process that is possibly more intense the less effective the reticuloendothelial system is to remove abnormal circulating cells (it is common for sickle cell patients to be functionally asplenic after preschool age, in a process called autosplenectomy). Free hemoglobin oxidizes into methemoglobin, liberating heme groups and ferrous ions. Freed arginase in the extracellular environment consumes L-arginine, a substrate for the endothelial synthesis of nitric oxide. Nitric oxide is directly consumed in the oxidation of hemoglobin to methemoglobin and in the neutralization of heme groups and ferrous ions. The oxidative lesion, direct consumption and deficit of nitric oxide synthesis cause endothelial activation, release of inflammatory and thrombogenic factors and a tendency to vasoconstriction. Permanent vascular injuries occur over the long term, perhaps fostered by chronic tissue hypoxemia and the synthesis of vasoproliferative substances. ${ }^{8}$ Secondary or simultaneous sinusoidal blockage by deformed red blood cells in the microcirculation and worsening of the local process of hemolysis may occur (the vicious cycle theory associates here as a corollary of the process) (Figure 1).9,10

In priapism these new concepts have specific implications, as the physiologic mechanisms of erection are specifically controlled by nitric oxide. Notably, priapism is more frequent in the severe forms of SCD, with an association to pulmonary hypertension (up to five times more common than in other SCD patients) and strokes. ${ }^{8,11}$ Episodes of priapism are also linked to a rise in serum markers

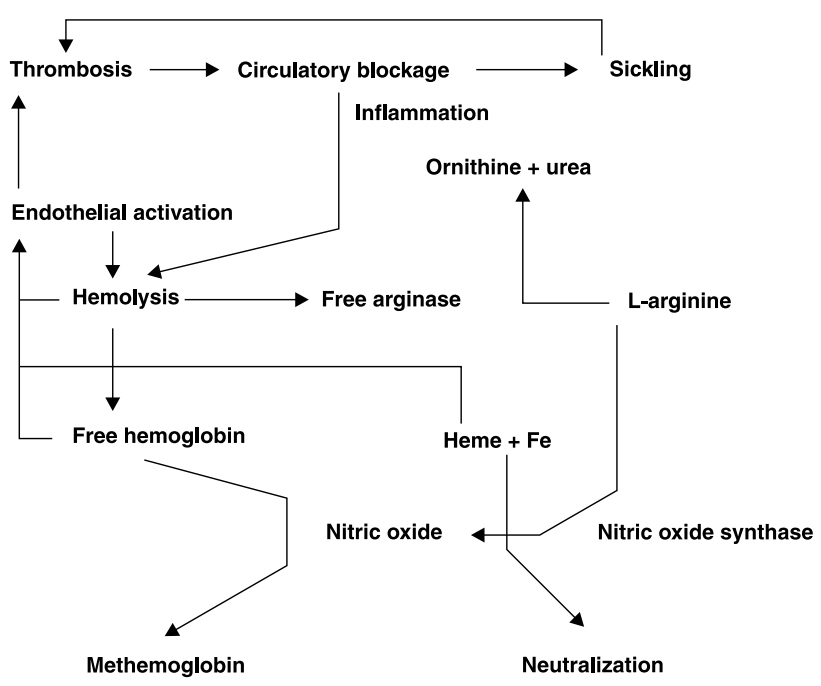

Figure 1 - Mechanisms of microcirculatory lesions in sickle cell disease: hemolysis, endothelial activation, hemoglobin gelation with sickling, microthrombosis, decline in production and excess consumption of nitric oxide

of hemolysis, such as increase of reticulocytes, indirect bilirubin, and lactate dehydrogenase (LDH). ${ }^{8,12,13}$

Normal erection is induced by the parasympathetic autonomic nervous system. Neural mediators determine the release of nitric oxide in the $\mathrm{CC}$, provoking a local increase of cyclic metabolites (cGMP) by the activation of guanylate-cyclase. cGMP then incites the cellular efflux of calcium and the relaxation of smooth muscle of efferent (helicine) arteries and of the CC itself, increasing afferent blood flow. The draining venules, anatomically located between the $\mathrm{CC}$, are passively compressed by the turgid and rigid corpora and blood accumulates. At the end of the process, generally signaled by ejaculation and orgasm, the sympathetic nervous system determines the vasoconstriction of the efferent arteries of the $\mathrm{CC}$, reducing the blood inflow. Venous drainage mechanisms them predominate and detumescence results. Nitric oxide is the main physiologic mediator of erection, by the mechanisms described, but other accessory biochemical processes are also likely to play an important role.

The description of erection - dependent on the release and local control of nitric oxide - and the contemporary ideas regarding endothelial activation and relative microvascular loss of nitric oxide in SCD suggest a relationship between the disease, chronic erectile problems and priapism. Chronic deficiency of nitric oxide provides a negative feedback on phosphodiesterase in the $\mathrm{CC}$. It has been postulated that this enzyme deficiency leads to uncontrolled erection episodes (priapism), caused by increases in cGMP by nitric oxideindependent mediators. Simultaneously the mechanisms of normal erection are hampered, in an apparent paradox. Based on this idea, the pharmacological inhibition of 
phosphodiesterase could make possible a rebalance at a new level of function (Figure 2 ). ${ }^{8}$

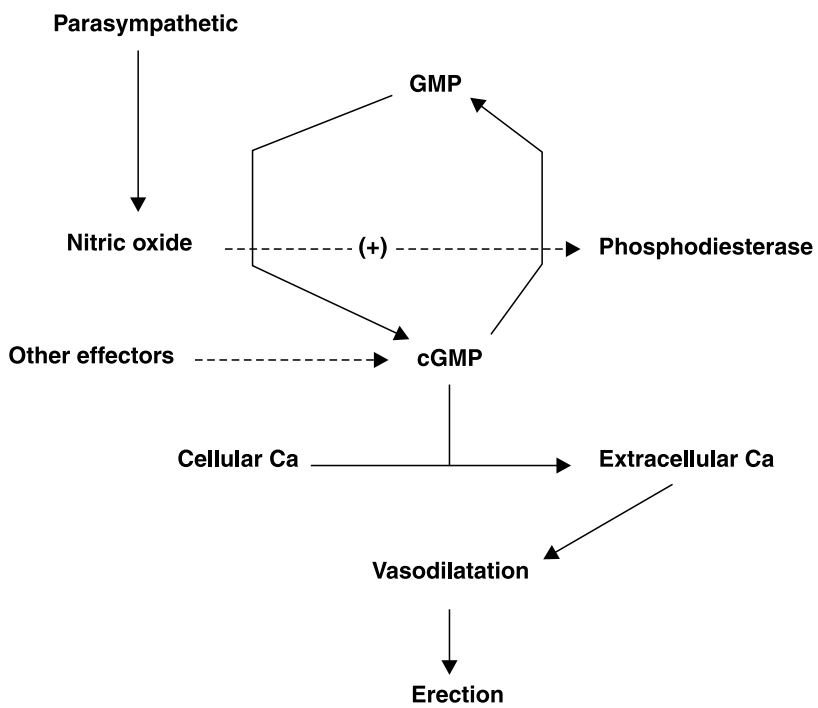

Figure 2 - Mechanisms determinant of erection: relations between nitric oxide and phosphodiesterase

\section{Definitions and epidemiology}

Priapism is defined as a non-physiologic persistent erection that is either not provoked by sexual stimulus or persists after ejaculation and orgasm. It normally involves the CC and spares the spongiosum (tricorporal priapism is uncommon and has poor prognosis). The problem was first reported in SCD patients in 1934 in its most frequent form of recurrent self-limited short episodes (stuttering episodes in the English literature). Acute episodes are defined as painful erection and/or persisting more than 4-6 hours. Approximately $2 / 3$ of patients presenting with an acute attack of priapism relate previous intermittent episodes.

A classification of priapism episodes as high or low flow has evolved during the $1980 \mathrm{~s},{ }^{14}$ and became essential to suggest causality and to determine prognosis and treatment. High flow episodes are characterized by an increase of arterial supply to the CC: venous drainage remains normal. Their prognosis is better, they usually do not have to be addressed as emergencies and secondary impotence is rare $(<20 \%)$. In children high flow priapism is typically caused by post-traumatic arteriocavernosal fistula (from penile, perineal or pelvic trauma), and is generally manifested several days after the trauma. It can also be caused by intracavernosal injections of vasoactive agents, scorpion or snake bites, substance abuse (mainly cocaine, which can cause high or low output priapism), some therapeutic drugs (especially psychiatric medications with autonomic nervous system effects), infectious diseases or tumors.
On low flow priapism there is a loss of vascular regulation. Venous drainage is impaired, presumably as a consequence of vascular blockage by deformed red blood cells. The situation may be further complicated as the fixed resistance maintained by the adventitia of the CC causes a compartment syndrome. This is an emergency and should be resolved within 6 hours of the onset of the episode to minimize the sequelae. In addition to $S C D$, other hematologic diseases with hypercoagulability or hyperviscosity (principally leukemias) and several drugs can cause low flow priapism.

SCD priapism may occasionally be of high output type, arising from a defect in the regulation of vascular tone in the CC, but it is estimated that more than $80 \%$ of sickle cell episodes are low flow (although the specialized literature seldom proves that, clinical presentation of acute pain suggests this is the case). On the other hand, it is known that conversion between the two forms of priapism is possible (cases of impotence after episodes of high flow perhaps might be due to conversion to low flow), especially in prolonged episodes, possibly by modifications in the regulation of afferent vascular tone.

Considering the high taxes of miscegenation of the black population of African origin (up to $40 \%$ of those carrying SCD genotype) to other ethnic groups in Brazil, the prevalence of sickle cell anemia in our country is very high. Textbooks suggest that the frequency of priapism in children with SCD varies between 2 and $6 \% .{ }^{15}$ Incidence statistics are adversely affected by a serious selection bias: only children seen in hospitals for acute episodes, specialty clinics and tertiary referral centers tend to be captured.

More than $1 / 4$ of priapism episodes in urologic practice are caused by SCD. In children nearly all cases of priapism are secondary to sickle cell anemia or trauma. At least $1 / 3$ of male adults with SCD present this symptom at some point, usually beginning in school age (the mean age for the onset of manifestations is 11 years), but it is rare to present this symptom for the first time after the third decade of life. ${ }^{1}$ Nearly $1 / 4$ present during the prepubertal period. ${ }^{1,16}$ Nocturnal episodes are more frequent. ${ }^{17}$ Priapism varies in frequency across the different ethnic groups with SCD. An absolute majority relates intermittent episodes preceding an acute episode, which emphasizes the need to investigate stuttering episodes in sickle cell outpatients, in order to actively prevent acute episodes and educate the patients. The most common precipitants are sexual activity (including masturbation), dehydration, fever and exposition to a cold environment.

\section{Diagnosis}

The physical examination detects an erection restricted to the $\mathrm{CC}$. The spongiosum and the glans remain flaccid, except for the rare cases of tricorporal priapism. Because 
of the lack of involvement of the periurethral spongiosum, there are normally no micturating problems.

In high flow cases the erection is less rigid and the penis is pink and pulsatile. There can be signs of trauma (hematomas, bruises). It may be possible to resolve the erection compressing the arteriovenous fistula feeder vessel, but the erection will recur immediately after the compression is withdrawn. In low flow cases the penis is rigid, extremely painful and seems ischemic: it does not pulse, is pale or grayish and cold. These manifestations are more evident after the episode has evolved for at least 4 hours.

To investigate a patient presenting with ischemic priapism the following laboratory studies should be ordered:

- Complete blood count and coagulation profile (to evaluate the degree of anemia, to detect signs of other hematologic diseases and to investigate a possible triggering infection);

- A search for sickle cells in a blood sample (if there is no prior diagnosis of SCD);

- Hemoglobin electrophoresis;

- Urinalysis and urine culture;

- An arterial blood gas analysis should be obtained if there is any suspicion of hypoxemia or systemic acidosis.

The distinction between high and low flow priapism can be established by the analysis of blood aspirated from the CC. In low flow cases blood will be dark, acidotic $(\mathrm{pH}<7)$, hypoxemic $\left(\mathrm{pO}_{2}<40 \mathrm{mmHg}\right)$ and hypercarbic $\left(\mathrm{pCO}_{2}>70 \mathrm{mmHg}\right)$. In high flow cases it will be bright red (arterial), alkalotic $(\mathrm{pH}>7)$, with normal oxygenation $\left(\mathrm{pO}_{2}>60 \mathrm{mmHg}\right)$ and low $\mathrm{pCO}_{2}(<70 \mathrm{mmHg}) .{ }^{18}$

Use of scintigraphy has been proposed to differentiate low (decreased uptake, "cold" CC) from high flow cases, but the limited availability of the test, its low specificity and sensitivity and the lack of a comparative or gold standard has limited its use. There are no studies comparing cavernosal blood analysis to cavernosal scintigraphy in sickle cell priapism. Unfortunately, the few published studies tend to view sickle cell priapism as low flow by definition. ${ }^{15}$

Doppler ultrasound is more useful for high flow cases, to identify an arteriovenous fistula supplying the erection. Cavernosography is rarely used, because blood analysis is adequate and less aggressive. Arteriography of the internal pudendal artery has some limited use in high flow cases in which there is an intention to treat by embolization or surgery (where it is important to locate the fistula that will be addressed by the surgeon or radiologist).

\section{Prognosis}

The prognosis for erectile function in sickle cell patients is poor. ${ }^{19}$ Most authors report that between $1 / 4$ to $1 / 2$ of patients become impotent after prolonged episodes of priapism. The prognosis may be better for prepubertal children.20 We could find no explanations for this phenomenon. Perhaps the absence of androgenic activity could explain the relative protection of prepubertal patients. The frequently suggested association between impotence and surgical treatment ( $1 / 4$ to $1 / 2$ of operated cases) should be questioned. There is a strong selection bias, as surgery has been systematically reserved for the most serious and advanced cases, not responsive to other interventions and low and high flow episodes are not systematically qualified in published reports. The use of different surgical techniques also makes it difficult to compare data from published manuscripts.

Acute cases have a much poorer prognosis than cases of intermittent priapism. In addition to impotence, erectile dysfunction and aversion to sexual activity (as the patient fears to induce episodes of priapism) are common. Cerebral vascular accidents are more frequent close to an episode of acute priapism. The ASPEN syndrome (association of sickle cell disease, priapism, exchange transfusion and neurological events), describes strokes in SCD patients who have undergone exchange transfusions. ${ }^{12,13}$

\section{Treatment}

For high flow priapism treatment is elective. Compression and ice packs while waiting for the spontaneous resolution of small fistulas (up to 6 weeks, according to most authors), embolization or surgery are the common suggestions.

In cases of low flow priapism, the latency between effective treatment and the beginning of an episode determines the prognosis for erectile function. There are serious difficulties in evaluating treatments for sickle cell priapism, because of the nearly complete absence of good quality evidence in the literature (only one study was considered to be of adequate quality for analysis among all studies examined in a recent Cochrane Collaboration systematic review). ${ }^{21}$

Men with SCD should be alerted regarding the need to seek prompt specialized treatment for any episode of priapism that lasts longer than 2 hours. Eighty-six percent of SCD patients do not spontaneously report complaints regarding intermittent priapism during regular consultations because of cultural factors, absence of perception of the phenomenon as abnormal (especially in children and adolescents), shame or a lack of understanding of the relationship of the phenomenon to SCD. The physician must actively inquire about priapism in the anamnesis of any SCD patient.

Ischemia can be demonstrated by cavernosal blood analysis 4 to 6 hours into an episode. After 12 hours interstitial edema begins. In 48 hours it is possible to detect necrosis of smooth muscle and invasion by fibroblasts. Later biopsies of the CC demonstrate fibrosis. This sequence suggests that histological lesions are already 
present after the 12th hour into the episode; thus, ideally, intervention should be able to end the episode before this time period. 22

Even before seeking care, the patient should be instructed to drink plenty of liquids, urinate, take a warm bath, use analgesics and undertake physical activity. Some cases will resolve spontaneously. If the episode does not resolve in 2 hours, it is critical that the patients seek medical care (or, according to a protocol that we consider inappropriate for pediatric patients, it is possible to self-administer an injection of an $\alpha$-adrenergic - see below). All patients should receive routine treatment for the complications of SCD: generous venous hydration (approximately twice normal requirements), oxygen, systemic alkalinization, analgesia and/or sedation. Some authors propose, without scientific basis, use of cold enemas. The intense discomfort and the risk of hypothermia (which is greater in pediatric patients) advise against this treatment. The use of ice packs on the penis (standardized in the cases of high flow priapism) is debatable in low flow cases, because presumably it would diminish the blood supply and increase ischemia, although it has analgesic effects and possibly limit cellular damage due to ischemia (cryoprotection). Despite its traditional use there is no available scientific evidence.

Exchange transfusions have been questioned for three main reasons:

- Absence of good quality scientific evidence of its efficacy ${ }^{13}$;

- Consideration of new ideas regarding the pathophysiology of SCD, progressing from red blood cell deformity and mechanical circulatory blockade to primary endothelial activation and vascular decompensation ${ }^{23}$;

- Risks associated with transfusion, considering the classic hazards of infectious diseases transmission, immunologic risks and ASPEN syndrome (possible induction of a stroke in sickle cell patients transfused for treatment of an episode of priapism), ${ }^{11}$ in addition to the logistical difficulties for obtaining blood for emergency exchange transfusions.

Next on treatment of any low flow priapism episode the $\mathrm{CC}$ can be aspirated and irrigated. The procedure is performed under local anesthesia in adults, but sedation in pediatric patients is advised, considering the low cooperation of children with a painful therapeutic procedure that consumes a relatively long time and the potential for worsening in SCD patients submitted to stress. Anesthesia for SCD has specific risks and requires special care. Rigorous asepsis should be followed: the most frequent complications of the procedure are infectious. Antibiotic prophylaxis is advised, using first-generation cephalosporins as the first choice.

After local anesthetic blockade, one of the CC is punctured, usually via the glans (in the majority of cases it is not necessary to access the two CC, which communicate): irrigation and drainage of the full extension of the corpora is more efficient using the most distal access available. A 21-gauge needle is typically used for children. For adolescents and adults, a 19-gauge needle can be used. First of all, blood should be collected for gas analysis and confirmation of the diagnosis. Thereafter the $\mathrm{CC}$ are drained. The volume removed in the aspiration should be limited to a maximum of $7.5 \mathrm{~mL} / \mathrm{kg}(10 \%$ of the blood volume in children $>1$ year of age), because of the risk of provoking hypovolemia or shock. Alphaadrenergic agonists - generally non-selective (etilefrine, phenylephrine, epinephrine, metaraminol) - are then injected. The exact pharmacologic action of these drugs to solve an episode of priapism is debatable: they may induce a constriction of afferent arteries, increasing venous return ( $\alpha$ effect), dilatation of vascular smooth muscle ( $\beta$ effect) or have other actions over the local vessels, ignored at the present time. ${ }^{17}$ Besides the risk of infection, the injection of adrenergic agents can be complicated by hematomas, urethral lesions, and fibrosis at the injection site. There are case reports of penile necrosis, only in adults and after prolonged episodes, one of them after a secondary necrotizing infection. ${ }^{24}$ Systemic effects are extremely rare. The proposed dosages are:

- Adrenaline 1:1,000,000: dose $10 \mathrm{~mL}$ (87\% success rate overall, $100 \%$ success in cases whose evolution was $<24$ hours). In $20 \%$ of cases it was necessary to repeat the injection. ${ }^{25}$ Other authors propose diluting $1 \mathrm{~mL}$ of adrenaline $1: 1,000$ solution in $1 \mathrm{~L}$ of saline and injecting $20 \mathrm{~mL}$ in repeated boluses, until a maximum of 10 injections $(200 \mathrm{~mL}) .^{26}$

- Etilefrine: Gbadoe et al. propose use of 5-10 mg per intracavernosal injection, without dilution. The authors report resolution in five of six episodes (lasting 4-28 hours). In a maximum follow-up of 4 years, no cases of impotence were related. Other authors suggest this same protocol for home management of priapism episodes, by self-administered injections. ${ }^{27}$

Also recommended for the control of acute episodes, as second choices:

- Intracavernosal injection of methylene blue. Postulated action: capture (scavenging) of oxygen-free radicals and/or inhibition of guanylate cyclase. Experience was with a few cases in adult patients (injection of $50 \mathrm{mg}$ ), none with SCD. ${ }^{28,29}$ Local infectious complications (CC abscess) and penile discoloration have been reported.

- Phosphodiesterase inhibitors: a deficiency of phosphodiesterase has been demonstrated experimentally in priapism, possibly related to defects in the regulation of erection (phosphodiesterase downregulation; see above). Some clinical experience was published in acute cases of SCD priapism in adults, with a single oral dose of $50 \mathrm{mg}$, resolving the episode within $90 \mathrm{~min}$ in all patients. 30

- Ketamine injections $(0.5-1 \mathrm{mg} / \mathrm{kg})$ : the mechanism of action is not understood, but may be dependent on 
the modulation of the autonomic nervous system and penile vascular tone. There are some published clinical reports in adults and children, which have been highly questioned. 31,32

- Hydralazine: only one case has been published, in a 16 year-old patient. The authors suggest that the vasodilatory action of the drug resolved the symptoms. ${ }^{33}$

- Calcium-channel blockers, possibly by directly modulating the mechanisms of erection. Few cases were reported, restricted to adults. There are various other published studies describing priapism secondary to use of these agents. ${ }^{34}$

- Anticoagulants: their use is based on the inhibition of local thrombogenic mechanisms. Doses and effects are poorly defined in the literature, which advocates direct use in the CC. ${ }^{35}$

- Corticosteroids, possibly acting as anti-inflammatory effect and by controlling the release of mediators from the activated endothelium.

- Continuous epidural anesthesia, possibly modifying the activity of the autonomic nervous system. ${ }^{36}$

- Inhaled nitric oxide. ${ }^{37}$

- Surgery: most authors would indicate surgery only in low flow priapism episodes, after 12 hours, if conventional medical treatment and injection of the $\mathrm{CC}$ with adrenergics could not solve the problem. This can be performed by a distal cavernosa-spongiosum shunt (Winter shunt, which creates a cavernosa-spongiosum shunt by puncturing the glans with a Tru-Cut needle and Al-Ghorab shunt, which proposes to suture the distal extremity of the CC to the spongiosum into the glans) or a proximal shunt (Grayhack shunt: laterolateral spongiosum to proximal penile CC suture) or by cavernosa-venous diversion (to the saphenous vein or to the dorsal vein of the penis). In an extensive review of the literature, Khoriaty et al. reported normal potency in $62 \%$ patients $(n=65)$ treated with saphenous-cavernous shunts $(74 \%$ in patients $<40$ years of age, $73 \%$ of unilateral vs. $55 \%$ of bilateral shunts), but described serious complications (pulmonary embolism and penile necrosis). Of 32 cases of spongiosum-cavernous anastomoses, $63 \%$ preserved potency ( $70 \%$ of the patients younger than 40 years). The complications reported were limited to urethral fistulas. ${ }^{38}$

Prophylaxis of recurrence of acute episodes or of occurrence of acute episodes in patients with recurrent self-limited priapism (considered as prodromes for acute episodes) has the following therapeutic proposals:

- Oral administration of $\alpha$-adrenergics: $0.5 \mathrm{mg} / \mathrm{kg}$ etilefrine at night or divided into two daily doses (maximum of $30 \mathrm{mg} / \mathrm{d}$ ), associated with intracavernosal self-injection in cases of acute episodes lasting more than 1 hour. $25,27,39$

- Terbutaline: only one group published a clinical report about use of this drug. ${ }^{40}$

- Therapy with hydroxyurea, with the aim of inducing the synthesis of fetal hemoglobin, modifying the mechanisms of endothelial activation and resulting in general improvement of SCD. Given the side effects and risks, this approach has been reserved for serious cases. Despite this, the association of priapism and stroke in SCD patients and the serious impact on the sexual life of young patients have prompted use of the drug in those cases, although it remains controversial among specialists. ${ }^{12,41,42}$

- Use of anti-androgenic hormonal manipulation, using gonadotrophin inhibitors (goserelin, leuprolide) or finasteride to reduce androgen levels to those attained by castration. This treatment, although efficacious, is fraught with side effects usually unacceptable to patients (loss of libido and erectile function). In pediatric patients iatrogenic persistent alteration of the still immature hypothalamus-pituitary-gonadal axis is theoretically possible. This treatment is costly. There is no sufficient evidence in the literature regarding its efficacy and safety. In the case of finasteride, there is no significant activity of androgens in pre-pubertal children that would justify usage of the drug. Those drugs are second- or third-line treatment options. ${ }^{17}$

- Estrogens/diethylestilbestrol: mechanism of action unknown. It is believed to be anti-androgen or to change the function of affected red blood cells. All available studies have treated adult patients (none refers to children). In a prospective placebo-controlled study of excellent technical quality the drug is extremely effective, but its use is limited by the recurrence of symptoms 6 to 8 weeks after discontinuation of the medication and because of the side effects (loss of libido and erectile function, gynecomastia, testicular atrophy). It should be considered a last resort medication, not appropriate for use in pre-pubescent patients. ${ }^{17}$

- Phosphodiesterase inhibitors: a single published article addressed only the successful prophylactic use in four adult patients (three with SCD) who had frequent recurrences and no response to other forms of therapy. 43

- Ketoconazole, for its mild anti-androgen effect. ${ }^{44,45}$ All cases reported in the literature are short-term postoperative use after penile surgery in patients without hematologic disease, and there are some theoretical worries with respect to the induction of resistance with the prolonged use of an antifungal drug.

The placement of a penile prosthesis should be considered in adulthood, so that patients with erectile dysfunction as a consequence of prior crises can become sexually active.

\section{Conclusions}

The clinical and surgical management in cases of priapism involving patients with SCD is full of controversies: in fact, there is no clinical evidence of great quality available at the moment. A change in the understanding of the pathophysiology of the disease can dramatically alter the therapeutic proposals in the near future. Well-designed 
prospective studies, preferably multicenter, given the small samples available in individual services, are urgently needed.

Considering the serious potential complications, it is important to educate patients and physicians for the importance of early detection of recurrent episodes of priapism (stuttering), in order to prevent acute cases. The careful classification of episodes into high and low flow episodes using cavernosal blood analysis and prompt care of acute cases of low flow priapism is essential to increase the chances of less aggressive but effective treatment with a lower incidence of permanent sequelae.

\section{References}

1. Adeyoju AB, Olujohungbe AB, Morris J, Yardumian A, Bareford D, Akenova $A$, et al. Priapism in sickle-cell disease; incidence, risk factors and complications - an international multicenter study. BJU Int. 2002;90:898-902.

2. Ham TH, Castle WB. Relationship of increased hypotonic fragility and of erythrostasis to the mechanism of hemolysis in certain anemias. Trans Assoc Am Physicians. 1940;55:127-32.

3. Klinefelter HF. The heart in sickle cell anemia. Am J Med Sci. 1942; 203:34-51.

4. Henderson AB, Thornell HE. Observations on the effect of lowered oxygen tension on sicklemia and sickle cell anemia among military flying personnel. J Lab Clin Med. 1946;31:769-76.

5. Sproule BJ, Halden RE, Miller WF. A study of the cardiopulmonary alterations in patients with sickle-cell disease and its variants. J Clin Invest. 1958;37:486-95.

6. Stockman JA, Nigro MA, Mishkin MM, Oski FA. Occlusion of large cerebral vessels in sickle cell anemia. $N$ Engl J Med. 1972;287:846-9.

7. Powars D, Weidman JA, Odom-Maryon T, Niland JC, Johnson C. Sickle cell chronic lung disease: prior morbidity and the risk of pulmonary failure. Medicine (Baltimore). 1988;67:66-76.

8. Kato GJ, Gladwin MT, Steinberg MH. Deconstructing sickle cell disease: reappraisal of the role of hemolysis in the development of clinical subphenotypes. Blood Rev. 2007;21:37-47.

9. Firth PG. Anaesthesia for peculiar cells - a century of sickle cell disease. Br J Anaesth. 2005;95:287-99.

10. Firth PG, Head CA. Sickle cell disease and anesthesia. Anesthesiology. 2004;101:766-85.

11. Siegel JF, Rich MA, Brock WA. Association of sickle cell disease, priapism, exchange transfusion and neurological events: ASPEN syndrome. J Urol. 1993;150:1480-2.

12. Nolan VG, Wyszynski DF, Farrer LA, Steinberg $\mathrm{MH}$. Hemolysis-associated priapism in sickle-cell disease. Blood. 2005; 106:3264-7.

13. Merritt $A L$, Haiman $C$, Henderson SO. Myth: blood transfusion is effective for sickle cell anemia-associated priapism. CJEM. 2006;8:119-22.

14. Hauri D, Spycher M, Bruhlman W. Erection and priapism: a new physiological concept. Urol Int. 1983;38:138-45.

15. Miller ST, Rao SP, Dunn EK, Glassberg KI. Priapism in children with sickle cell disease. J Urol. 1995;154:844-7.

16. Liu J, Al-Hothari MA, Mahboob FA. Non surgical treatment of recurrent or stuttering priapism in sickle cell children. Saudi Med J. $2003 ; 24: 1143-5$

17. Maples BI, Hagemann TM. Treatment of priapism in pediatric patients with sickle cell disease. Am J Health Syst Pharm. 2004;61:355-63.

18. Van der Horst C, Stuebinger H, Seif C, Melchior D, MartinezPortillo FJ, Juenemann KP. Priapism: etiology, pathophysiology and management. Int Braz J Urol. 2003;29:391-400.

19. El-Banasawy MS, Dawood A, Farouk A. Low flow priapism: risk factors for erectile dysfunction. BJU Int. 2002;89:285-90.

20. Chacrabarty A, Upadhyay J, Dhabuwala CB, Sarnaik S, Perlmutter AD, Connor JP. Priapism associated with sickle cell hemoglobinopathy in children: long-term effects on potency. J Urol. 1996;155:1419-23.
21. Chinegwundoh F, Anie KA. Treatments for priapism in boys and men with sickle cell disease Cochrane Database Syst Rev. 2004;(4): CD004198.

22. Pflueger A, Blackwell KA, Sampson SM. 38-year-old man with priapism and a history of paranoid schizophrenia. Mayo Clin Proc. 2005;80:111-4.

23. Burnett AL. Pathophysiology of priapism: dysregulatory erection physiology thesis. J Urol. 2003;170:26-34.

24. Montoya Martinez G, Otero Garcia JM, Lopez Samano V, Gonzalez Martinez J, Serrano Brambilla E. Penile necrosis: a review of 18 cases at the Hospital de Especialidades Centro Medico Nacional Siglo XXI. Arch Esp Urol. 2006;59:571-6.

25. Mantadakis E, Ewalt DH, Cavender JD, Rogers ZR Buchanam GR. Outpatient penile aspiration and epinephrine irrigation for young patients with sickle cell anemia and prolonged priapism. Blood. 2000;95:78-82.

26. Molina I, Bejany D, Lynne CM, Politano VA. Diluted epinephrine solution for the treatment of priapism. J Urol. 1989; $141: 1127-8$

27. Gbadoe AD, Atakouma Y, Kusiaku K, Assimadi JK. Management of sickle cell priapism with etilefrine. Arch Dis Child. 2001;85:52-3.

28. Martínez Portillo F, Hoang-Boehm J, Weiss J, Alken P, Jünemann $\mathrm{K}$. Methylene blue as a successful treatment alternative for pharmacologically induced priapism. Eur Urol. 2001;39:20-3.

29. Steers WB, Selby JB Jr. Use of methylene blue and selective embolization of the pudendal artery for high flow priapism refractory to medical and surgical treatments. J Urol. 1991;146:1361-3.

30. Bialecki ES, Bridges KR. Sildenafil relieves priapism in patients with sickle cell disease. Am J Med. 2002;113:252.

31. Ravindran RS, Dryden GE, Somerville GM. Treatment of priapism with ketamine and physostigmine. Anesth Analg. 1982;61:705-7.

32. Appadu B, Calder I. Ketamine does not always work in treatment of priapism. Anaesthesia. 1991;46:426-7.

33. Baruchel S, Rees J, Bernstein ML, Goodyer P. Relief of sickle cell priapism by hydralazine. Report of a case. Am J Pediatr Hematol Oncol. 1993;15:115-6.

34. Russell JM, MacGregor RJ, Watson L. Prazosin and priapism. Med J Aust. 1985;143:321.

35. Francis RB. Large-vessel occlusion in sickle cell disease: pathogenesis, clinical consequences, and therapeutic implications. Med Hypotheses. 1991;35:88-95.

36. McHardy $P$, McDonnell $C$, Lorenzo AJ, Salle JL, Campbell FA. Management of priapism in a child with sickle cell anemia; successful outcome using epidural analgesia. Can J Anaesth. 2007; 54:642-5.

37. Burnett AL, Musicki B, Jin L Bivalacqua TJ. Nitric oxide/ redoxbased signaling as a therapeutic target for penile disorders. Expert Opin Ther Targets. 2006;10:445-57.

38. Khoriaty N, Schick E. Surgery for priapism. J Urol (Paris). $1980 ; 86: 283-91$

39. Bachir D, Virag R, Lee K, Belloy M de Montalembert M, Denis L, et al. Prevention and treatment of erectile disorders in sickle cell disease. Rev Med Interne. 1997; 18 Suppl 1:46s-51s.

40. Ahmed I, Shaikh NA. Treatment of intermittent idiopathic priapism with oral terbutaline. Br J Urol. 1997;80:341.

41. Okpala I. Investigational agents for sickle cell disease. Expert Opin Investing Drugs. 2006;15:833-42.

42. Saad ST, Lajolo C, Gilli S, Marques Junior JF, Lima CS, Costa FF, et al. Follow-up of sickle cell disease patients with priapism treated by hydroxiurea. Am J Hematol. 2004;77:45-9.

43. Burnett AL, Bivalacqua TJ, Champion HC, Musicki B. Long-term oral phosphodiesterase 5 inhibitor therapy alleviates recurrent priapism. Urology. 2006;67:1043-8.

44. Stock JA, Kaplan GW. Ketoconazole for prevention of postoperative penile erections. Urology. 1995;45:308-9.

45. Evans KC, Peterson AC, Ruiz HE, Costabile RA. Use of oral ketoconazole to prevent post-operative erections following penile surgery. Int J Impot Res. 2004;16:346-9.

\section{Correspondence:}

Lisieux Eyer de Jesus

Rua Presidente Domiciano 52/801

CEP 24210-270 - Niterói, RJ - Brazil

Tel.: +55 (21) 2622.3843, +55 (21) 9985.9737

E-mail: lisieux@uol.com.br 